\title{
Wavelet Based Fault Detection and Classification Algorithm for a Real Distribution Feeder
}

\author{
Hatice Okumus, Fatih M. Nuroğlu \\ Electrical and Electronics Engineering \\ Karadeniz Technical University, Trabzon, Turkey \\ haticeokumus@ktu.edu.tr,fmn@ktu.edu.tr
}

\begin{abstract}
As the importance of protection in power systems increase, knowing the type of malfunction occurring in the system has become crucial. Especially in the distribution system where electricity is delivered to the consumer, detecting the right fault type with a short amount of time is important. For this purpose in this study, Akyazı-Düzköy distribution feeder in Trabzon/Turkey, where faults commonly occur, is modeled with Digsilent Powerfactory. The model is performed with actual parameters including 465 lines, 243 loads, 233 transformers and 1093 busbars. First, the load flow and short circuit analysis have been carried out for the validation of the model. Then a fault detection and classification algorithm is enhanced using the wavelet transform and the energy of the coefficients. Different types of short circuit faults are created at different points on the model to test the accuracy of the algorithm. The fault inception time and the effect of the fault resistance are also investigated.
\end{abstract}

Keywords: Distribution System, Fault Detection, Digsilent Powerfactory, Wavelet Transform, Trabzon.

\section{INTRODUCTION}

Electrical energy has become indispensable in every area of our lives and for this reason, it should be provided with high quality. The quality of electrical energy depends on the continuity and reliability of the system. This will be possible by reducing the outage time and taking the right interventions with the detection of power system faults.

Many studies have been carried out in this area regarding the detection of fault and fault type. Adly and et al. [1] combined the merits of discrete wavelet transform (DWT) and Karen Bell Transformation for the fault analysis process. The proposed algorithm was tested on a $350 \mathrm{~km}, 500 \mathrm{kV}$ transmission line using ATP/EMTP simulation package. Fault location, fault resistance, fault inception angle and different source capacities were validated using the algorithm. Affijulla and Tripathy [2] developed a robust fault detection and discrimination technique for transmission lines. The 
algorithm was tested on IEEE 14-bus test system, six generator 23-bus system and the reduced NERES 25 bus Indian power system with PSS/Sincal software. The relay tripping decision was made with the fault detection and discrimination technique. Also, signal phasor estimation was carried out using the Hilbert Transform. Guillen and et al. [3] detected and classified faults in transmission lines based on DWT and singular value decomposition (SVD) using the current signals. Simulations were done in Digsilent Powerfactory using both WSCC 9 bus test system and own modeled system containing 4 busbars. The effect of fault impedance and inception time was also investigated. K-NN based fault detection and classification methods for power transmission systems were studied by Majd and et al [4]. Fault resistance, occurrence time, location, $\mathrm{X} / \mathrm{R}$ ratio and phase angle effects were investigated in the simulations. In addition to these studies, fault detection in HV transmission lines [5], fault classification with Haar wavelet transform [6], wavelet-fuzzy combined approach for fault classification and location [7] and many others [8-10] can be found in the literature for transmission lines.

The studies have not only been limited to transmission lines but also a lot of work has been done on distribution lines [11-14]. Alves and Fonseca [15], have modeled a 282 non-transposed distribution feeder in ATP/EMTP software in order to detect faults by applying the discrete wavelet transform to the current signals. Ghaderi and et al. [16], studied a high impedance fault detection in the distribution network using the time-frequency-based algorithm. Oliveira and et al. [17], have enhanced a Fault classification in distribution systems based on fault current angles. The algorithm is based on Artificial neural networks associated with fault current angles information and classifies series, shunt and simultaneous faults with cable on the source or on the load. The proposed scheme was tested on IEEE 13 and 34-bus test system.

The aforementioned studies are mostly for test systems, not for real distribution feeders. In real distribution systems, it is difficult to detect the occurred faults especially for long-distance distribution lines with a branched structure in the rural area. In this study, a real distribution feeder containing 465 lines, 243 loads, 233 transformers and 1093 busbars is modeled in Digsilent Power Factory. The reliability of the model is investigated with load flow and short circuit analysis and satisfying result have been attained. For fault detection and classification, a wavelet transform and a Clarke transformation based algorithm is developed using the model current signals. Different types of faults are created at different locations in order to validate the proposed algorithm. Fault resistance and fault inception time are also investigated in the study. Compared to other studies, this study will contribute to the literature in terms of developing a fault detection algorithm by using current signals obtained from a real distribution feeder model with high reality. 


\section{SYSTEM MODELING}

\subsection{Modeling Real Distribution Feeder Located in Trabzon/Turkey}

It is important in terms of system reliability and continuity to predict the consequences of failures in electrical networks. In this regard, network analysis programs provide an important convenience. Digsilent Powerfactory program is one of these analysis programs and the network modeling can be done as well as load flow analysis, voltage level and short circuit analysis, protection coordination, dynamic and harmonic simulation, Electromagnetic Transient (EMT) analysis and many more [18]. As a result of reviews and negotiations with ÇORUH EDAŞ, it has been detected that faults frequently occur on Akyazı-Düzköy feeder, therefore it is appropriate to use this feeder in this study.

Akyazı TM is a substation which provides energy by reducing the line voltage of $154 \mathrm{kV}$ to $31.5 \mathrm{kV}$ with a $100 \mathrm{MVA}$ transformer. From the Akyazl Distribution Center (DM); Trabzon Fideri1, Trabzon Fideri2, Trabzon Fideri3, Düzköy fideri, Akçaabat Fideri and Söğütlü fideri, a total of 6 feeder exits. Akyazı-Düzköy feeder first enters the Uğurlu DM and then the Kayalar Kök and then energy is distributed to related units. This feeder contains 465 lines, 243 loads, 233 transformers and 1093 busbars. The model parameters are provided by ÇORUH EDAȘ. Using the provided data, Akyaz-Düzköy feeder was modeled as in Figure 1. 


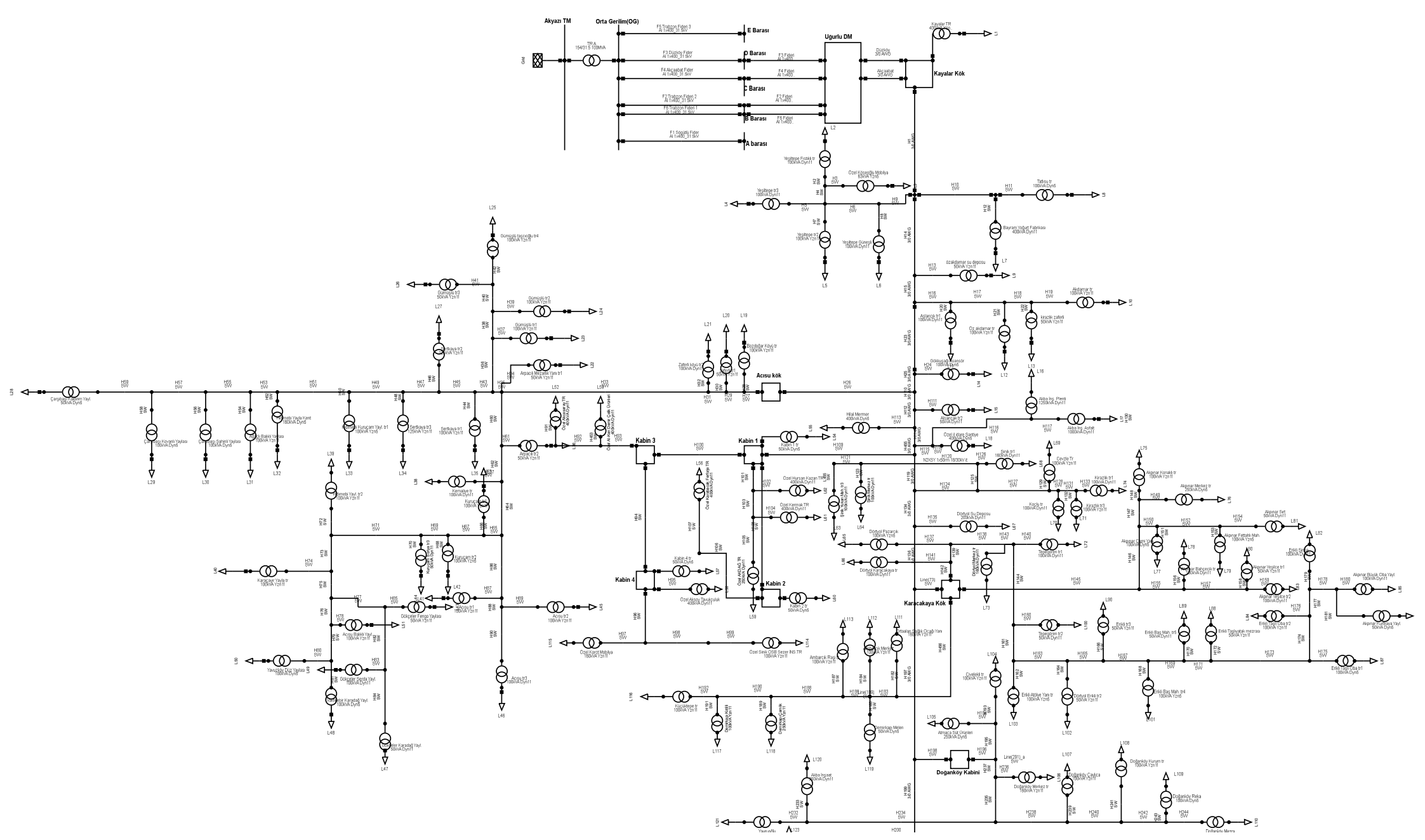

(a)

EMITTER International Journal of Engineering Technology, ISSN: 2443-1168 


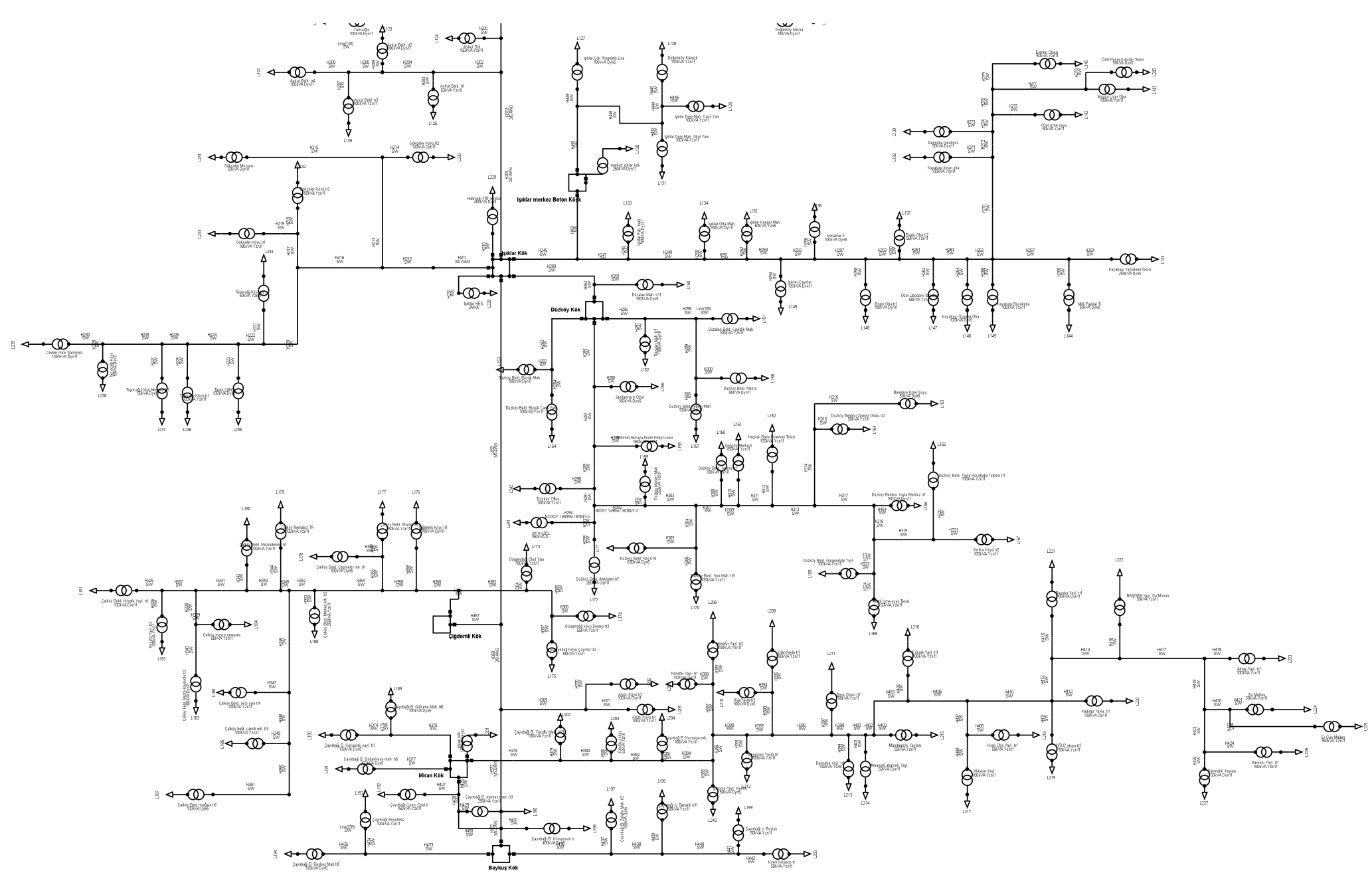

(b)

Figure 1. Model of Akyazı-Düzköy Feeder 


\subsubsection{Load flow analysis}

The Load flow is a numerical steady-state analysis to ensure that the network is operating in the best possible way and to foresee if the system can handle any future problems by pre-planning. Load flow analysis of the feeder modeled in Digsilent Powerfactory program is carried out to see how close the model is to reality by using daily load flow values of Akyazi-Düzköy feeder provided by ÇORUH EDAŞ and shown in Figure 2.

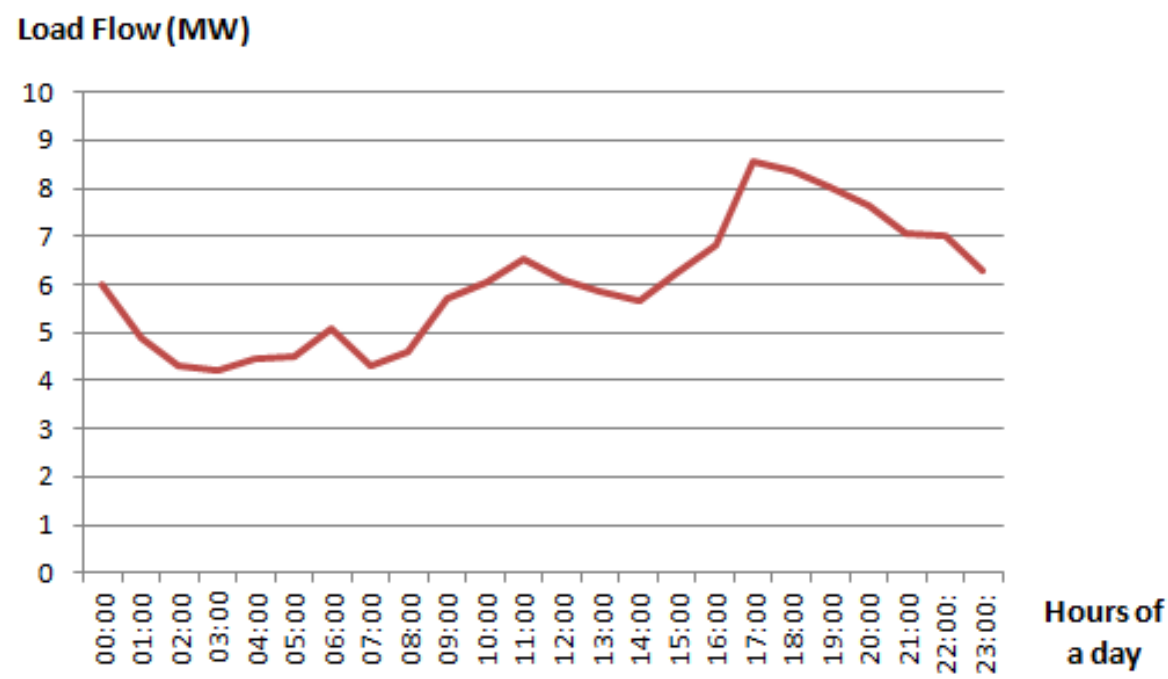

Figure 2. Daily load flow values of Akyazı-Düzköy feeder analysis;

3 different hours of the day are selected from the above figure for the

- 5,083 MW at 06:00

- 6,526 MW at 11:00

- 7,624 MW at 20:00

According to the chosen hours and load values, the load scaling amounts are determined and the analysis of selected busbars are carried out.

In the 1 st case, the load scaling amount is determined as 0.165 for 5,083 MW at 06:00 and the voltage values of selected busbars are given in Table 1.

Table 1. The load flow analysis for 0.165 scaling amount

\begin{tabular}{ccc} 
Selected Points & Voltage(kV) & Voltage(p.u., per unit) \\
\hline \hline Acısu Kök & 31,7 & 1,01 \\
Karacakaya Kök & 31,6 & 1 \\
Doğanköy Kök & 31,5 & 1 \\
Merkez Beton Köşk & 31,4 & 1 \\
Işıklar Kök & 31,4 & 1 \\
Düzköy Kök & 31,4 & 1 \\
Çiğdemli Kök & 31,3 & 0,99 \\
Miran Kök & 31,3 & 0,99 \\
Baykuş Kök & 31,3 & 0,99
\end{tabular}


In the second case, the load scaling amount for the 6,526 MW at 11:00 is determined as 0,212 and the voltage values of selected busbars are given in Table 2 .

Table 2. voltage values for scaling amount of 0.212

\begin{tabular}{ccc} 
Selected Points & Voltage(kV) & Voltage(p.u., per unit) \\
\hline \hline Acısu Kök & 31,4 & 1 \\
Karacakaya Kök & 31,2 & 0,99 \\
Doğanköy Kök & 31,1 & 0,99 \\
Merkez Beton Köşk & 31 & 0,98 \\
Işlklar Kök & 31 & 0,98 \\
Düzköy Kök & 31 & 0,98 \\
Çiğdemli Kök & 30,90 & 0,98 \\
Miran Kök & 30,8 & 0,98 \\
Baykuş Kök & 30,9 & 0,98
\end{tabular}

In the 3rd case, the load scaling amount for the 7,624 MW is set to 0.245 at 20:00 and the voltage values of selected busbars are given in Table 3.

Table 3. Voltage result for 0.245 scaling amount

\begin{tabular}{ccc} 
Selected Points & Voltage(kV) & Voltage(p.u., per unit) \\
\hline \hline Acısu Kök & 31,3 & 0,99 \\
Karacakaya Kök & 31 & 0,98 \\
Doğanköy Kök & 30,9 & 0,98 \\
Merkez Beton Köşk & 30,7 & 0,97 \\
Işılklar Kök & 30,7 & 0,98 \\
Düzköy Kök & 30,7 & 0,97 \\
Çiğdemli Kök & 30,60 & 0,97 \\
Miran Kök & 30,5 & 0,97 \\
Baykuş Kök & 30,6 & 0,97
\end{tabular}

\subsubsection{Short Circuit analysis}

Faults in the power system reduce the insulation power of the conductors and damage the system. The causes of these faults can be listed as; lightning, severe winds, natural elements such as earthquakes, aircraft crashes and so on. 
It is possible to comment on the fault just by looking at the current and voltage signals obtained from the Digsilent model. Figure 3 shows the 3 phase current-voltage signals when a fault occurs on line H432. Considering the voltage signals given in Figure 3, a significant decrease in phase a and a small decrease in phases b-c can be seen. When the current signals are considered, a significant increase is observed in phase a. If the signals are examined and the theoretical background is taken into consideration, it is possible to determine what kind of fault occurred in the line. It is expected that the voltage value in the phase where the short circuit occurs will decrease while the value of the drawn current in the same phase is reduced, so it is possible to foresee that the fault occurring in the signals indicated in Figure 3 is a single-phase ground fault and this fault occurs in phase a.

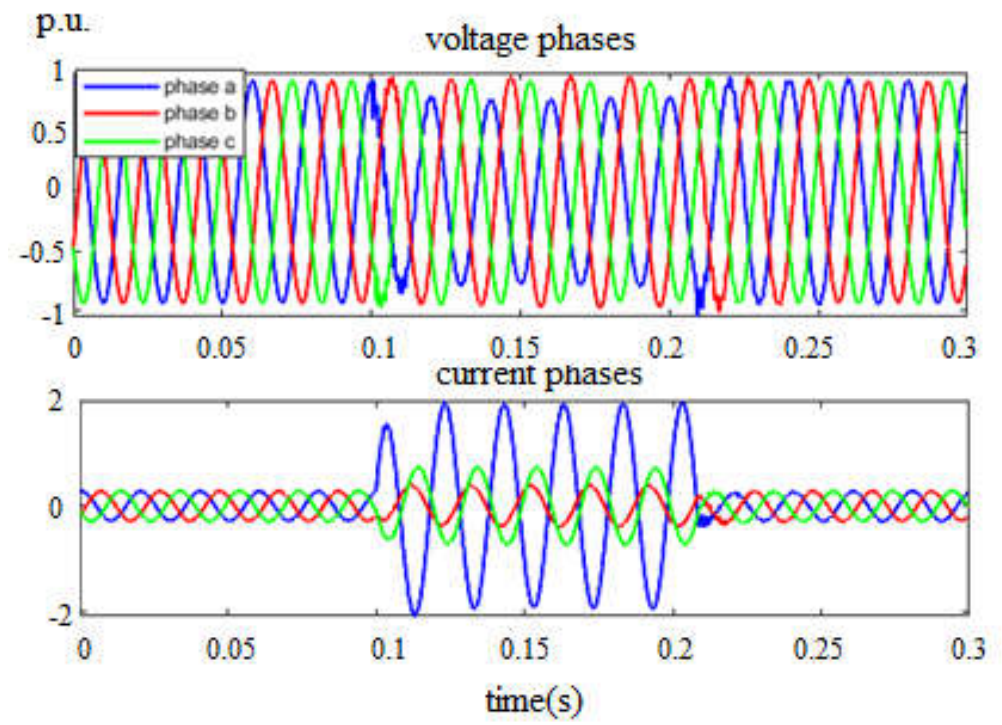

Figure 3. Voltage and current signals for a single-phase ground fault

\section{FAULT DETECTION AND CLASSIFICATION ALGORITHM}

In the algorithm, firstly wavelet transform is applied to the current data obtained from the modeled feeder. Then, the existence of fault is detected. At this stage, each phase signal is examined at half-period intervals to see if the amplitude change exceeds the specified threshold. The point at which the threshold is exceeded is determined as the inception point of the fault. "No fault" warning is given if the threshold value is not exceeded in any phase. If the fault is present, the energy value of each phase signal is found in order to determine the fault type. Whether the fault is grounded or not is discovered with the mode 0 data obtained from Clarke transform. If the value of mode 0 is too low, there is no grounding. 


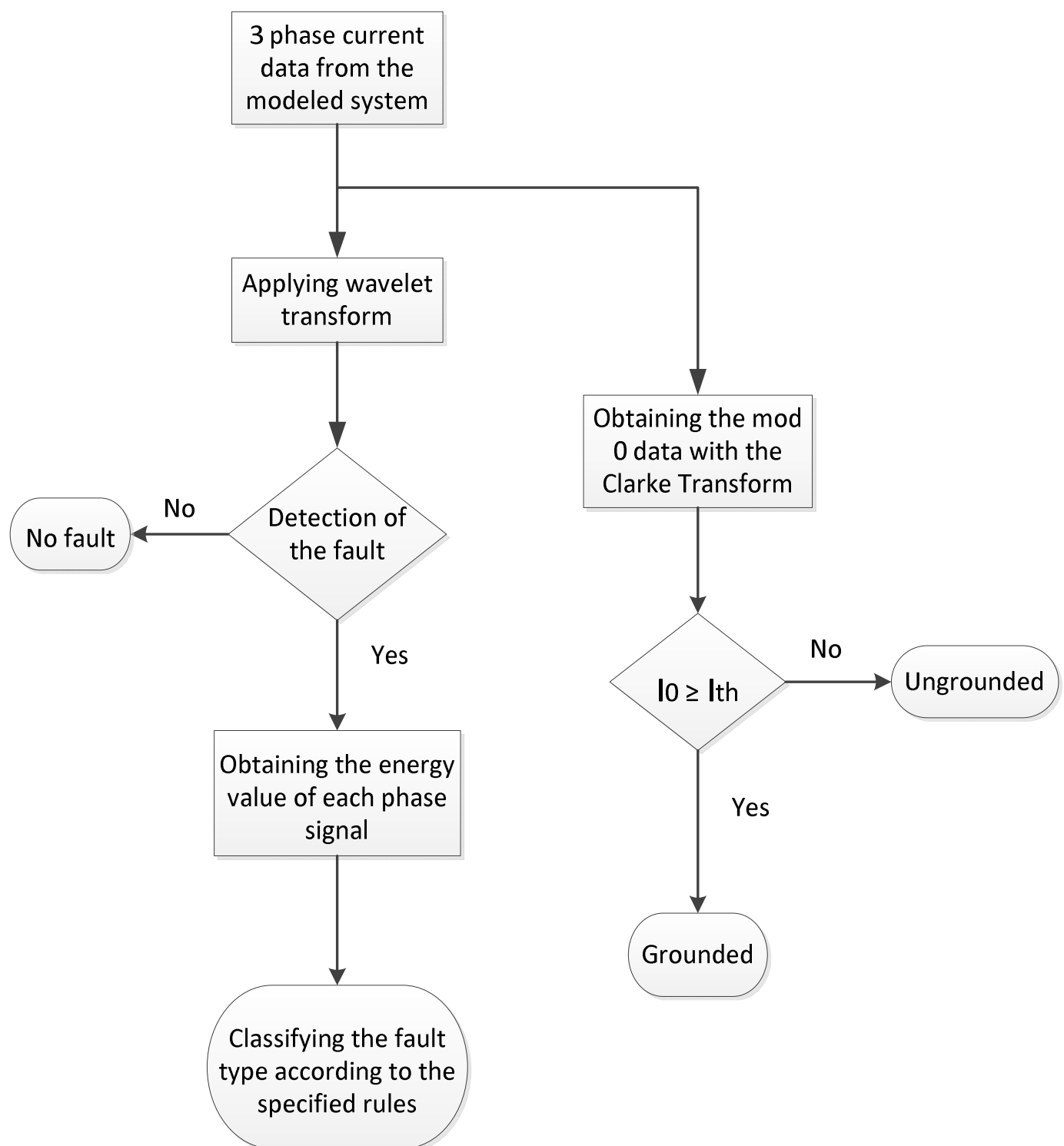

Figure 4. Flowchart of the algorithm

\subsection{Wavelet Transform}

The Wavelet Transform is a feature extraction method widely used in the literature. The advantage of this method is that it has both time and frequency components and it ensures narrow windows for high frequencies, large windows for low frequencies helping the entire frequency range to be examined.

In this study, the continuous wavelet transform (CWT) coefficients are used and are obtained as in (1).

$$
C W T(x, y)=x^{-1 / 2} \int_{-\infty}^{+\infty} Y(t) \psi\left(\frac{t-x}{y}\right) d t
$$


$Y(t)$ represents the sign itself, $\psi(t)$ represents the wavelet function, $x$ and $y$ represents the scale and step magnitude respectively.

\subsection{The Energy of the Wavelet Coefficients}

After extracting the wavelet coefficient of each current phase signals, it is possible to detect the faulty phase by obtaining the energy values of the current signals as shown in Eq. (2)

$$
E=\sum_{n=1}^{N}[x(n)]^{2}
$$

where $x(n)$ is the $\mathrm{n}$-th wavelet coefficient of the raw current phase signal, $\mathrm{N}$ is the total number of coefficients.

When the energy signals given in Figure 5 are taken into consideration, it can be seen that the energy value of the faulty phase is high and in the faultless phase this value is low.

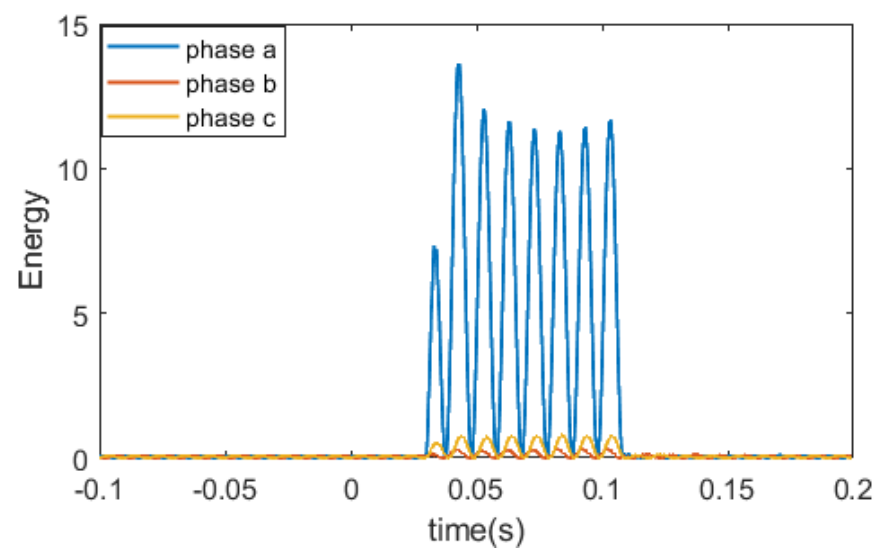

(a) phase a-ground fault

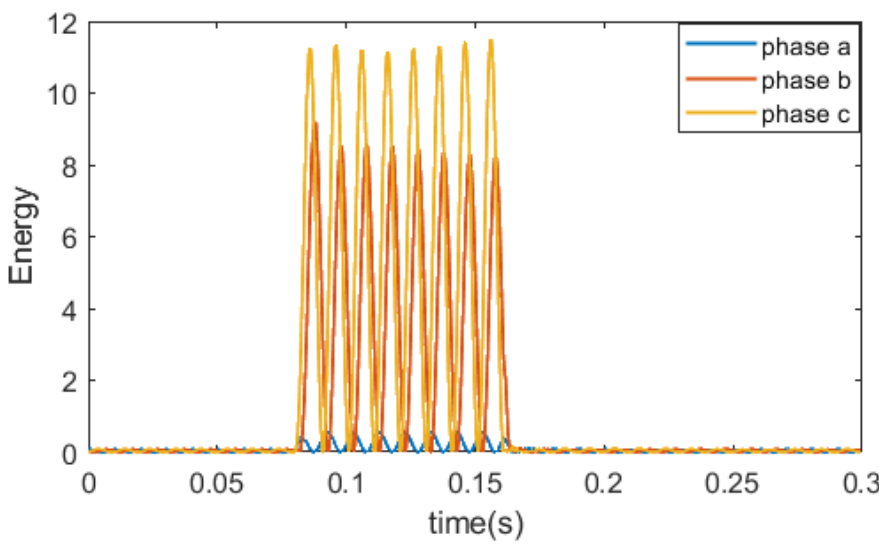

(b) phase b- phase c-ground fault

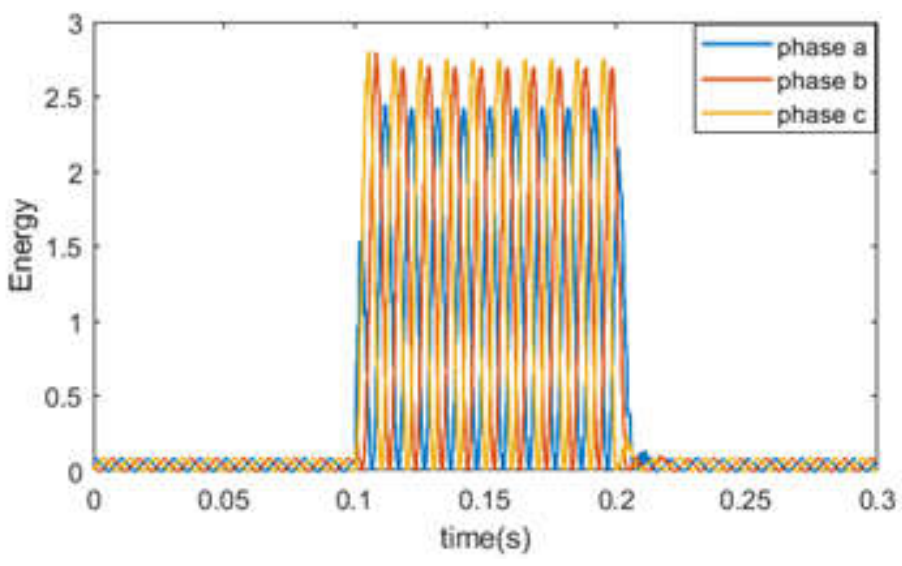

(c) three phase fault

Figure 5. Energy signals for different fault types 


\subsection{Clarke Transformation}

In three-phase systems, the current and voltage waves do not have a constant speed due to the strong electromagnetic effect between the conductors. In literature, modal transformation matrices of Clarke, Wedepohl and Karrenbauer are frequently used to obtain a constant wave velocity. 3-phase current signals can be transformed into modal components, as in (3) by Clarke's transformation matrix [19].

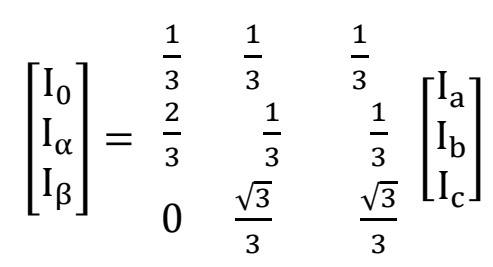

There are 3 modes in total; mode 0 (ground mode), mode $\boldsymbol{\alpha}$ and mode $\boldsymbol{\beta}$ (ariel mods). Due to the excess of information contained in the signal, mode $\alpha$ and mode $\beta$ are highly preferred when finding the fault location. Whereas, mode 0 only gets value when there are ground faults, so it can be used to determine the fault type. In (3); $I_{a}, I_{b}, I_{c}$ represent the threephase current signals while $\mathrm{I}_{0}, \mathrm{I}_{\alpha}, \mathrm{I}_{\beta}$ represent the ground mode, $\alpha$ mode and $\beta$ mode of the transformed phase current signals respectively.

In Figure 6, the ground modes of current signals belonging to two different fault type are illustrated. While the ground mode signal of singlephase ground fault shows great changes, the two-phase fault mod 0 signal shows little changes when faults occur between $0.15-0.25$ seconds.

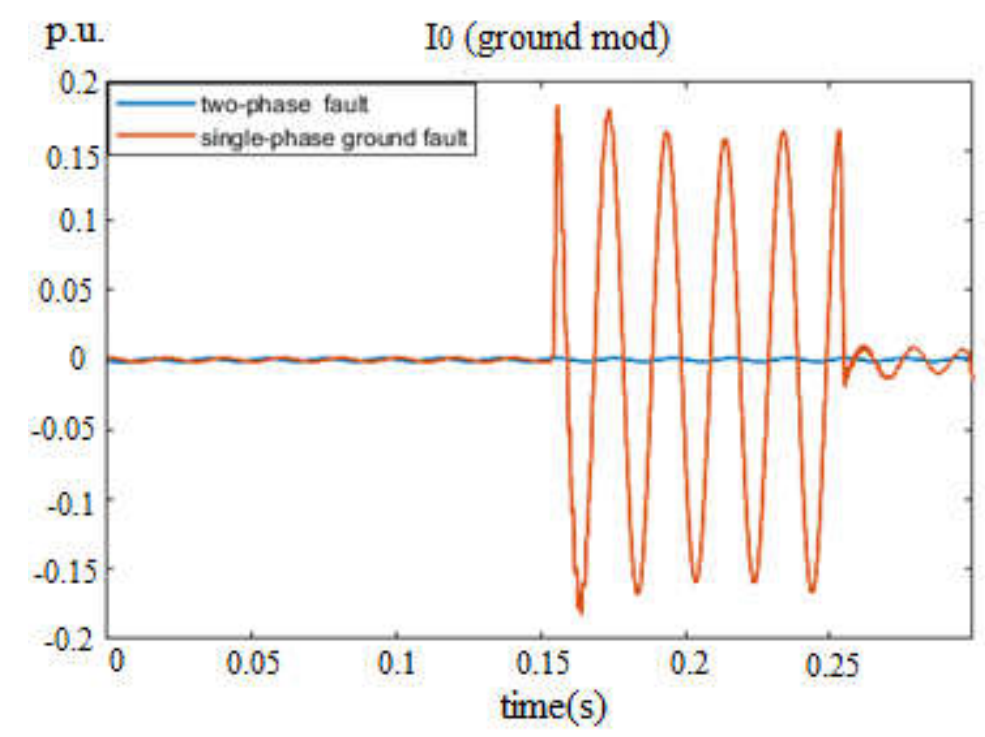

Figure 6. Ground mod signals for different fault types 


\section{RESULTS}

For the validation of the algorithm, different types of faults located in different lines are created on Akyzi-Düzköy feeder model. The simulations are carried out in Digsilent Power Factory (EMT simulations) with a $1 \mathrm{kHz}$ sampling frequency. Faults are applied at different inception times during a $300 \mathrm{~ms}$ simulation each. The signals are transported to MATLAB and the performance of the algorithm is tested here.

Table 4 presents the results for different types of faults with different fault impedances. Faults generated on the feeder have been formed on different lines and the efficiency of the algorithm on the general distribution feeder has been investigated.

Table 4. Result for fault type detection

\begin{tabular}{|c|c|c|c|}
\hline $\begin{array}{l}\text { Fault } \\
\text { type }\end{array}$ & $\begin{array}{c}\text { Fault } \\
\text { resistance }(\Omega)\end{array}$ & $\begin{array}{c}\text { Fault } \\
\text { location }\end{array}$ & $\begin{array}{l}\text { Detected } \\
\text { fault type } \\
\end{array}$ \\
\hline$\overline{A G}$ & & $\mathrm{H} 26$ & $\overline{A G}$ \\
\hline $\mathrm{BC}$ & 5 & H216 & BC \\
\hline ACG & & Н313 & ACG \\
\hline $\mathrm{ABC}$ & & $\mathrm{H} 410$ & $\mathrm{ABC}$ \\
\hline $\mathrm{AG}$ & & H26 & $\mathrm{AG}$ \\
\hline BC & 15 & H216 & BC \\
\hline ACG & & H313 & ACG \\
\hline $\mathrm{ABC}$ & & H410 & $\mathrm{ABC}$ \\
\hline $\mathrm{AG}$ & & $\mathrm{H} 26$ & $\mathrm{AG}$ \\
\hline $\mathrm{BC}$ & 30 & H216 & $\mathrm{BC}$ \\
\hline ACG & & H313 & $\mathrm{AC}$ \\
\hline $\mathrm{ABC}$ & & H410 & $\mathrm{ABC}$ \\
\hline $\mathrm{AG}$ & & $\mathrm{H} 26$ & AG \\
\hline $\mathrm{BC}$ & 40 & H216 & BC \\
\hline ACG & & H313 & $\mathrm{AC}$ \\
\hline $\mathrm{ABC}$ & & H410 & $\mathrm{ABC}$ \\
\hline
\end{tabular}

In Table 5, the effectiveness of the algorithm on finding the correct inception time of faults in different locations and types is investigated. When the results are examined, it is seen that in some values of inception time the algorithm is operating perfectly while in other inception time values it is not. The reason for this is mostly the size of the window used to determine whether the fault exists or not. Based on the results it can be said that the algorithm will give a maximum time delay of $9 \mathrm{~ms}$. 
Table 5. Result for detection of inception time

\begin{tabular}{|c|c|c|c|c|}
\hline $\begin{array}{l}\text { Fault } \\
\text { type }\end{array}$ & $\begin{array}{c}\text { Fault } \\
\text { resistance( }(\Omega)\end{array}$ & $\begin{array}{c}\text { Fault } \\
\text { location }\end{array}$ & $\begin{array}{c}\text { Fault } \\
\text { inception } \\
\text { time(s) }\end{array}$ & $\begin{array}{c}\text { Time } \\
\text { Delay(s) }\end{array}$ \\
\hline AG & \multirow{4}{*}{ " } & H26 & 0.18 & 0 \\
\hline $\mathrm{BC}$ & & H216 & 0.08 & 0 \\
\hline ACG & & H313 & 0.122 & 0.002 \\
\hline $\mathrm{ABC}$ & & $\mathrm{H} 410$ & 0.155 & 0.005 \\
\hline$\overline{\mathrm{AG}}$ & \multirow{4}{*}{15} & H26 & 0.18 & 0 \\
\hline $\mathrm{BC}$ & & $\mathrm{H} 216$ & 0.08 & 0 \\
\hline ACG & & H313 & 0.122 & 0.002 \\
\hline $\mathrm{ABC}$ & & $\mathrm{H} 410$ & 0.155 & 0.005 \\
\hline AG & \multirow{4}{*}{30} & H26 & 0.18 & 0 \\
\hline $\mathrm{BC}$ & & H216 & 0.08 & 0 \\
\hline ACG & & H313 & 0.122 & 0.002 \\
\hline $\mathrm{ABC}$ & & $\mathrm{H} 410$ & 0.155 & 0.005 \\
\hline AG & \multirow{4}{*}{40} & H26 & 0.18 & 0 \\
\hline $\mathrm{BC}$ & & $\mathrm{H} 216$ & 0.08 & 0 \\
\hline ACG & & H313 & 0.122 & 0.002 \\
\hline $\mathrm{ABC}$ & & $\mathrm{H} 410$ & 0.155 & 0.005 \\
\hline
\end{tabular}

As mentioned before, the fault detection and classification is carried out with the energy values of each phase signal and the current ground mod value. In Table 6, the obtained energy and ground mod values are clearly viewed regarding the fault types. As an example, the energy values of each phase are 3.754, 0.107, 0.193 respectively for AG fault with a 5 fault resistance located on line H26. From these values, it is obvious that the fault has occurred on phase A. Also with the high I0 value, it can be said that the fault is ground connected. 
Table 6. Phase energy values for different fault conditions

\begin{tabular}{ccccccc}
$\begin{array}{c}\text { Fault } \\
\text { type }\end{array}$ & $\begin{array}{c}\text { Fault } \\
\text { resistance( } \boldsymbol{\Omega})\end{array}$ & $\begin{array}{c}\text { Fault } \\
\text { location }\end{array}$ & $\mathbf{a}$ & $\begin{array}{c}\text { Energy } \\
\text { b }\end{array}$ & c & I0 \\
\hline \hline $\mathrm{AG}$ & & $\mathrm{H} 26$ & 3.754 & 0.107 & 0.193 & 0.347 \\
$\mathrm{BC}$ & 5 & $\mathrm{H} 216$ & 0.062 & 2.581 & 2.456 & 0.005 \\
$\mathrm{ACG}$ & & $\mathrm{H} 313$ & 1.537 & 0.140 & 1.304 & 0.102 \\
$\mathrm{ABC}$ & & $\mathrm{H} 410$ & 0.576 & 0.631 & 0.622 & 0.010 \\
\hline $\mathrm{AG}$ & & $\mathrm{H} 26$ & 1.511 & 0.088 & 0.119 & 0.204 \\
$\mathrm{BC}$ & \multirow{2}{*}{15} & $\mathrm{H} 216$ & 0.062 & 1.558 & 1.505 & 0.004 \\
$\mathrm{ACG}$ & & $\mathrm{H} 313$ & 0.921 & 0.126 & 0.816 & 0.080 \\
$\mathrm{ABC}$ & & $\mathrm{H} 410$ & 0.435 & 0.469 & 0.492 & 0.009 \\
\hline $\mathrm{AG}$ & & $\mathrm{H} 26$ & 0.651 & 0.077 & 0.089 & 0.120 \\
$\mathrm{BC}$ & \multirow{3}{*}{30} & $\mathrm{H} 216$ & 0.062 & 0.875 & 0.862 & 0.003 \\
$\mathrm{ACG}$ & & $\mathrm{H} 313$ & 0.531 & 0.108 & 0.502 & 0.061 \\
$\mathrm{ABC}$ & & $\mathrm{H} 410$ & 0.313 & 0.331 & 0.348 & 0.008 \\
\hline $\mathrm{AG}$ & & $\mathrm{H} 26$ & 0.454 & 0.073 & 0.081 & 0.095 \\
$\mathrm{BC}$ & \multirow{2}{*}{40} & $\mathrm{H} 216$ & 0.062 & 0.652 & 0.650 & 0.002 \\
$\mathrm{ACG}$ & & $\mathrm{H} 313$ & 0.407 & 0.100 & 0.397 & 0.051 \\
$\mathrm{ABC}$ & & $\mathrm{H} 410$ & 0.264 & 0.277 & 0.292 & 0.007
\end{tabular}

\section{CONCLUSION}

In this paper, analysis of a real distribution feeder modeled in Digsilent Power Factory is evaluated and a fault detection-classification algorithm is proposed. The proposed method is based on wavelet transform and signal energy combining with Clarke transform to detect the right fault type. The validation of the algorithm is carried out with the model data. The fault inception time and the effect of the fault resistance is also investigated. The results give high accuracy in different conditions.

\section{Acknowledgements}

The authors would like to thank ÇORUH EDAŞ electricity distribution company located in Trabzon/Turkey for providing the data required for the feeder modeling.

\section{REFERENCES}

[1] A. R. Adly, R. A. El Sehiemy, and A. Y. Abdelaziz, A novel single end measuring system based fast identification scheme for transmission line faults, Measurement, Vol. 103, pp. 263-274, 2017.

[2] S. Affijulla, and P. Tripathy, A Robust Fault Detection and Discrimination Technique for Transmission Lines, IEEE Transactions on Smart Grid, Vol. 9, No. 6, pp. 6348-6358, 2018.

[3] D. Guillen, M. R. A. Paternina, A. Zamora, J. M. Ramirez, and G. Idarraga, Detection and classification of faults in transmission lines using the maximum wavelet singular value and Euclidean norm, IET Generation, Transmission \& Distribution, Vol. 9, No.15, pp. 2294-2302, 2015. 
[4] A. A. Majd, H. Samet, and T. Ghanbari, k-NN based fault detection and classification methods for power transmission systems, Protection and Control of Modern Power Systems, Vol. 2, No. 1:32, 2017.

[5] A.R. Adly, R. A. El Sehiemy, A. Y. Abdelaziz, and N. M. Ayad, Critical aspects on wavelet transforms based fault identification procedures in HV transmission line, IET Generation, Transmission \& Distribution, Vol. 10, No. 2, pp. 508-517, 2016.

[6] K. M. Silva, et al., Haar wavelet-based method for fast fault classification in transmission lines, Transmission \& Distribution Conference and Exposition: Latin America, Caracas, pp. 1-5, 2006.

[7] M. J. Reddy and D. K. Mohanta, A wavelet-fuzzy combined approach for classification and location of transmission line faults, International Journal of Electrical Power \& Energy Systems, Vol. 29, No. 9, pp. 669-678, 2007.

[8] Z. He, L. Fu, S. Lin, and Z. Bo, Fault detection and classification in EHV transmission line based on wavelet singular entropy, IEEE Transactions on Power Delivery, Vol. 25, No. 4, pp. 2156-2163, 2010.

[9] D. Chanda, N. K. Kishore, and A. K. Sinha, Application of wavelet multiresolution analysis for identification and classification of faults on transmission lines, Electric Power Systems Research, Vol. 73 No. 3, pp. 323-333, 2005.

[10] S. El Safty, and A. El-Zonkoly, Applying wavelet entropy principle in fault classification, International Journal of Electrical Power \& Energy Systems, Vol. 31, No. 10, pp. 604-607, 2009.

[11] M. Shafiullah, and M. A. Abido, S-Transform based FFNN approach for distribution grids fault detection and classification, IEEE Access, Vol. 6, pp. 8080-8088, 2018.

[12] M. Kavi, Y. Mishra, and M. D. Vilathgamuwa, High-impedance fault detection and classification in power system distribution networks using morphological fault detector algorithm, IET Generation, Transmission \& Distribution, Vol. 12, No.15, pp. 3699-3710, 2018.

[13] U. D. Dwivedi, S. N. Singh, and S. C. Srivastava, A wavelet based approach for classification and location of faults in distribution systems, Annual IEEE India Conference, Kanpur, Vol. 2, pp. 488-493, 2008.

[14] M. Dehghani, M. H. Khooban, and T. Niknam, Fast fault detection and classification based on a combination of wavelet singular entropy theory and fuzzy logic in distribution lines in the presence of distributed generations, International Journal of Electrical Power \& Energy Systems, Vol. 78, pp. 455-462, 2016.

[15] H. N. Alves, and R. N. B. Fonseca, An algorithm based on discrete wavelet transform for fault detection and evaluation of the performance of overcurrent protection in radial distribution 
systems, IEEE Latin America Transactions, vol. 12, N0.4, pp. 602-608, 2014.

[16] A. Ghaderi, H. A. Mohammadpour, H. L. Ginn, and Y. J. Shin, Highimpedance fault detection in the distribution network using the time-frequency-based algorithm, IEEE Transactions on Power Delivery, Vol. 30, No. 3, pp. 1260-1268, 2015.

[17] A. R. Oliveira, P. A. N. Garcia, , L. W. Oliveira, E. J. Oliveira, and H. A. Silva, Fault Classification in Distribution Systems Bsaed on Fault Current Angles, IEEE Latin America Transactions, Vol. 14, No. 1, pp. 199-205, 2016.

[18] Power Factory Manual Version 2018.

[19] Ö. Sözen, Üretim Birimi İçeren Elektrik Dağıtım Sistemlerinde Arıza yeri belirlenmesinin incelenmesi, Master Thesis, Institute of Science and Technology, Istanbul Technical University, 2005. 